\title{
Um Sopro de Destruição de José Augusto de Pádua
}

\author{
Queila Amaro Rodrigues da Silva \\ Universidade Severino Sombra Centro de Letras, Ciências Sociais \\ Aplicadas e Humanas - Curso de História \\ queila.ar@hotmail.com
}

\begin{abstract}
PÁDUA, José Augusto de. Um Sopro de Destruição - Pensamento político e crítica ambiental no Brasil escravista, 1786-1888, Rio de Janeiro: Zahar, 2002.
\end{abstract}

Esta resenha tem como objetivo principal entender como os pensadores do final do século XVIII e quase todo o XIX, mais precisamente até a abolição da escravatura em 1888 - recorte temporal que o autor trabalha - viam a relação do homem com a natureza, a escravidão e como ambas as coisas estavam vinculadas entre si. Faremos isto de maneira sucinta nos detendo nos pontos que consideramos dignos de maior destaque, isto é, naqueles que dizem respeito à região do Rio de Janeiro e do Vale do Paraíba.

O livro que tomamos como base para nossa análise foi escrito na tentativa de compreender as preocupações ambientais que se faziam crescentes na sociedade brasileira da época e para tanto o autor se utilizou-se de diversos autores recolhendo um amplo material que tornou possível a execução de sua obra.

Em 1970 surgiu uma disciplina denominada História Ambiental, destinada a estudar, dentre outras coisas, como os seres humanos eram afetados pelo ambiente natural em que viviam e como, em contrapartida, afetavam-no também. Apesar de terem surgido ainda na década de setenta, os escritos relativos à História Ambiental são um tanto recentes no Brasil e é justamente nessa temática que se insere o trabalho de José Augusto de Pádua. O título "Um Sopro de Destruição" refere-se à escravidão que, por onde passava, deixava após si um rastro de destruição, isto é, os países que a adotavam colhiam frutos amargos de destruição, a exemplo do que estava acontecendo no Brasil.

O autor analisou, dentro dos cem anos estudados por ele, a existência de uma possível racionalidade econômica na extração e no uso dos recursos naturais no Brasil. Percebe-se que naquele momento havia no país uma inquietação em relação às questões econômicas, entre as quais tornaram-se evidentes as críticas ambientais. $\mathrm{O}$ motor propulsor para tais inquietações residia no interesse de que o país progredisse e no valor que o ambiente natural representava dentro do cenário político e capitalista. Figura entre as discussões da época problemas ambientais e socais como o desmatamento, as queimadas, a monocultura, a escassez de madeira e a exaustão das terras agrícolas, dentre outros.

O vínculo entre escravidão e destruição ambiental, ou seja, a escravidão como fator responsável por aquilo que era reconhecido como as mazelas do Brasil - o atraso econômico e social do país - já fora anunciado por José Bonifácio, entretanto entre os anos de 1840 a 1880 houve uma míngua de textos que fizessem relação entre ambos os elementos:

Mosaico - Revista Multidisciplinar de Humanidades, Vassouras, v. 3, n. 1, p. 63-68, jan./jun., 2012 
escravidão e destruição ambiental. Durante esse período os autores se limitaram a escrever e a propor reformas para os fatores que se associavam ao esgotamento do solo, tais como, o desmatamento, a monocultura e as queimadas e que, por conseguinte, se colocavam como causa direta do atraso sócio-econômico do país.

Foi no Brasil oitocentista, mais precisamente na literatura agrícola, que se desenvolveram as críticas ambientais das quais fizeram parte reflexões mais ou menos diretas ao escravismo. Pádua descreve em seu livro uma gama de autores que escreveram - durante esse período - motivados pelo contraste existente entre as riquezas naturais brasileiras e o caráter rudimentar de sua exploração efetiva.

Para Calmon (2002), a mentalidade destrutiva existente no Brasil fora herdada dos ibéricos e era responsável por gerar práticas extremamente ruinosas tanto para a economia rural como para a nação como um todo. $\mathrm{O}$ autor propunha a criação de uma política voltada para a conservação e o beneficiamento das matas que ainda restavam, bem como o replantio das zonas de retirada e o reflorestamento das propriedades rurais. Carlos Taunay (in Pádua, 2002) associava o atraso da agricultura à falta da adoção de tecnologias mais avançadas, porém não vinculou ao tal atraso a utilização da mão de obra escrava, antes propôs a criação de um código que combinasse os interesses dos senhores com o bem estar dos negros, ou seja, o autor defendia a manutenção das relações escravistas. Embora, esses indivíduos tenham participado da crítica ambiental e, no caso deste último, contribuído para o reconhecimento da importância das florestas percebe-se, afinal, que nenhum deles defendeu a necessidade imperiosa da abolição da escravatura.

Com respeito à plantação do café no Vale do Paraíba, Taunay criticou a maneira como esta cultura vinha sendo plantada - nas encostas, em linhas retas e verticais de baixo para cima - alegando que este método contribuía em grande medida para a erosão dos solos. Semelhantemente, o barão Werneck (idem, ibidem) preocupado com a expansão do café no Vale e os desmatamentos que antecediam estas plantações apresentou receio em relação àqueles que haviam de herdar tais terras. Entretanto, seus escritos não ofereceram grandes modificações no que tange às práticas predatórias: não propôs nenhuma mudança em relação à forma como era plantado o café, como fez Taunay; limitou-se apenas ao plantio de árvores e ao aproveitamento econômico das madeiras que eram queimadas. Já com relação à escravidão mostrou-se favorável, pois em seu dizer "é da conservação da escravatura que depende a prosperidade do fazendeiro". (idem)

A partir da segunda metade do século XIX, começaram a surgir abordagens que renovaram e ampliaram as perspectivas de análise crítica. Capanema, (2002) por exemplo, remontou ao período colonial na tentativa de apontar a origem do atraso da agricultura brasileira. Seguidamente, o autor propõe uma ruptura na medida em que analisa o novo contexto: era agora incompatível a manutenção dos antigos padrões produtivos; a realidade era outra: as terras se apresentavam cansadas e a mão de obra escrava, cara. Era, portanto, necessário para a obtenção do progresso que se rompesse com o que ele ousou chamar de "modelo nômade e agressivo" e que se adotassem medidas novas tais como a utilização do arado e a adubação com estrume e matérias orgânicas, o que por sua vez levaria à aquisição de uma lavoura fixa. Entretanto, o enfrentamento da mão de obra escrava passou despercebido em seu trabalho, de maneira que sua teoria sobrepujou a aplicação prática. 
Diferentemente, Pacova (in Pádua, 2002) trouxe à baila uma série de propostas baseadas num diagnóstico prévio que encerrava "a combinação de motivos" pelos quais a agricultura estava a definhar: a falta de tecnologias modernas, de instrução profissional e de crédito somadas às dificuldades de transportes, à escassez de braços e à destruição ambiental. Esta variedade de problemas reclamava um conjunto integrado de políticas. Pacova acrescentou às propostas reformistas anteriores a necessidade de diversificação das culturas, a disseminação da educação rural - mudança na mentalidade e, por conseguinte, das práticas dominantes - e, como elemento primordial, a substituição do trabalho escravo.

A disseminação dessas e outras ideias tiveram fomento a partir da criação da Revista Agrícola em 1869. Um artigo publicado por Miguel Silva fez associação das práticas predatórias herdadas dos ibéricos com o nomadismo cuja essência consistia na seguinte atitude: quando um solo se apresentava esgotado migravam para outro. Dessa forma os problemas relativos ao esgotamento dos solos foram escamoteados através do nomadismo até o ápice da crise da lavoura brasileira.

Depois da Lei do Ventre Livre, em 1871. ficou evidente que o sistema escravista vivia os últimos dias na sociedade brasileira e, a partir de então, a imigração foi amplamente defendida como meio de conter o problema da falta de mão de obra. Neste tempo o lavrador de Paraíba do Sul - Manoel Ribeiro do Val - observou que o Município de Vassouras, outrora o mais rico produtor de café, mostrava agora a exaustão do seu solo. De igual modo encontravam-se as cidades produtoras da região do Vale do Paraíba e para lá caminhava a província do Rio de Janeiro. Ribeiro do Val defendia a criação de núcleos de colonização a exemplo do que estava sendo feito no sul do país.

Falando ainda sobre a decadência ambiental do Vale do Paraíba, Pádua destaca o clássico escrito por Stanley Stein sobre a cidade de Vassouras, onde esta aparece como um 'município de terras em decadência'. Nesta mesma linha escreveu Azevedo (2002), fazendeiro do município de Cantagalo, que, após detectar a cadeia de riscos que ameaçava a sobrevivência da sociedade brasileira, colocou em prática a salvação da fazenda de sua família, no município acima descrito. Em Moreira ( in Pádua, 2002) essas medidas marcavam a substituição do "labor ignorante" pela "atividade racional".

Paulatinamente, após a abertura da sociedade para o debate sobre o escravismo a partir da década de 1860, desenvolveu-se nos órgãos de imprensa e nas instituições culturais a repulsa pelo trabalho escravo. Neste ínterim a abolição passou a ser defendida como fator primeiro do progresso e não apenas como algo positivo ao mesmo tempo em que a escravidão passava a ser vista como um problema a ser enfrentado. Pádua escreve que

O grande diferencial do abolicionismo, dessa maneira, não esteve no plano da retórica. O passo radical foi o de estabelecer uma relação de causalidade forte entre o escravismo e o caráter decadente, atrasado e destrutivo da vida socioeconômica brasileira. (PÁDUA, 2002. p. 264) 
Desta maneira, o que diferenciava a crítica ambiental de agora - inaugurada por José Bonifácio e, posteriormente, retomada por André Rebouças e Joaquim Nabuco - era a relação causal entre escravidão e a destruição ambiental. Tal posição era nova no cenário das reflexões e discussões: as posições anteriores mesmo quando abordavam o tema da escravidão o faziam sem a relação de causalidade, isto é, tanto a destruição ambiental como a escravidão eram problemas desassociados que refletiam o atraso do país os quais podiam ser resolvidos através da modernização.

Os escritos de Rebouças (in Pádua) ficaram marcados pela maneira ardorosa como defendeu o progresso e o avanço da civilização nacional. $\mathrm{O}$ autor criticou, ainda, os barões escravocratas por esterilizarem as férteis terras do Vale do Paraíba. Desde que a agricultura fosse explorada com base nos princípios de racionalidade dos recursos naturais - pensava Rebouças - se constituiria como importante fonte de progresso e civilização para o país. As mudanças almejadas deveriam iniciar-se pela abolição da escravidão. Seguidamente, suas propostas abrangiam ainda a reforma agrária, o reflorestamento, a introdução das tecnologias, a diversificação da produção, a fertilização com estrumes e outras. Em suma,

\footnotetext{
A grande crise social, econômica e ambiental, pela qual passava o país poderia ser invertida, quase integralmente, por uma combinação de vontade política, reformas sociais, liberação da livre iniciativa e ciência e tecnologia. [...] A difusão do conhecimento científico seria o grande trunfo para o progresso da sociedade. [...] Mas a premissa de todas essas mudanças estava na abolição, na divisão das terras, na promoção da pequena propriedade cultivada pelo trabalho livre. (PÁDUA, 2002 p. 270)
}

Outro influente abolicionista desta época foi Joaquim Nabuco (In Pádua, 2002). Desde cedo, suas reflexões partiram do contraste existente entre o trabalho servil e a opulência brasileira. Em sua obra a escravidão aparecia como fator que impedia o surgimento de uma relação saudável com a terra. Mais que defender o fim da escravidão, o autor propunha a 'destruição da obra da escravidão', já que o conceito de escravidão para ele ia além da posse deste tipo de mão de obra incluindo também "todo o conjunto de mentalidades, práticas e instituições que haviam sido moldadas, influenciadas ou facilitadas pelo domínio do trabalho escravo". (PÁDUA, 2002, p. 273) A monocultura, os latifúndios, a ausência da tecnologia e da ética de valorização do trabalho, por exemplo, eram, nas palavras de Nabuco, heranças da 'obra da escravidão'.

É, portanto dentro deste contexto que se insere a região do Vale do Paraíba. A expansão da plantação do café nesta região se deve a dois motivos: à demanda do produto no mercado internacional e às práticas agrícolas que eram utilizadas rotineiramente (a queimada, por exemplo, esgotava o solo dentro de aproximadamente quatro anos), já que depois de esgotarem o solo forçavam a migração para outro ainda fértil - o que no dizer de Capanema era o modelo "nômade e agressivo". Desta forma, no século XIX a situação dessas terras já não era a mesma quanto à fertilidade daí o surgimento de vários autores que engrossavam o coro daqueles que pregavam o fim das práticas predatórias e, posteriormente da escravidão. 
Em suma, podemos depreender que a crítica ambiental dos autores supracitados teve grande significado dentro do cenário político e socioeconômico brasileiro. Mais que isso, elas desempenharam papel definitivo cujo ápice foi a abolição da escravidão em 1888. Se as propostas defendidas por eles foram de fato postas em prática e, se tiveram a eficácia esperada, é outro assunto, mas é certo que, com a libertação da mão de obra escrava, colocou-se a necessidade premente de substituir práticas que agora já não eram mais compatíveis. 


\section{Referências}

AZEVEDO, Luiz Corrêa de. (2002) “Da cultura do café. 1877”. In: PÁDUA, José Augusto, obra citada, p. 256 e 257.

CALMON, Miguel Du Pin e Almeida. (2002) "Ensaio sobre o fabrico do açúcar. 1834. In: TAUNAY, Carlos. "Manual do agricultor brasileiro". 1837. In: PÁDUA, José Augusto, idem, p. 237-41.

CAPANEMA, Guilherme. "Agricultura: fragmentos do relatório dos comissários brasileiros à Exposição Universal de Paris em 1855. 1858”. In: PÁDUA, José Augusto, idem, p. 244-247.

MOREIRA, Nicolau. “Indicações agrícolas. 1875 ”. In: PÁDUA, José Augusto, idem, p. 260-262.

NABUCO, Joaquim. “O abolicionismo.1883”. In: PÁDUA, José Augusto, idem, p. 272277.

PACOVA, Caetano da Rocha. "Apontamentos sobre a necessidade de uma escola de agricultura. 1859”. In: PÁDUA, José Augusto, idem, p. 247-250.

REBOUÇAS, André. “Agricultura Nacional. 1883”. In: PÁDUA, José Augusto, idem, 265-271.

TAUNAY, Carlos. “Manual do agricultor brasileiro. 1837.” In: PÁDUA, José Augusto, idem, p. 237-241.

WERNECK, Francisco Peixoto de Lacerda. (2002) "Memória sobre a fundação de uma fazenda na província do Rio de Janeiro. 1847”. In: PÁDUA, José Augusto, idem, p. 242 e 243. 